\title{
Sinonasal Angioleiomyoma: A Rare Entity
}

\author{
Rubeena Arora Shubh Mahindru Komal Kathuria
}

Ivy Superspecialty Hospital, Mohali, India

\section{What Is It about?}

Our case report is about the rare occurrence of a lesion known as angioleiomyoma in the nasal cavity of a 59-year-old male. Angioleiomyomas are benign tumors originating from smooth-muscle cells. Angioleiomyomas usually occur in the uterus in $95 \%$ of the cases, skin in $3 \%$ of the cases, and gastrointestinal tract in $1.5 \%$ of the cases. Incidence elsewhere in the body other than these is reported as being less than $1 \%$. This is one of the first cases being reported from North India.

\section{Keywords}

Head and neck tumors · Sinus surgery · Surgery

\section{Abstract}

The present case of angioleiomyoma of the nasal cavity in a 59-year-old male is unique, being the first case from North India and also because of its unique area of origin. The patient was referred to the Ear, Nose and Throat Outpatient Department with a diagnosis of an asymptomatic nasal mass. Biopsy done on the mass in another hospital reported angiofibroma. Excision was done after all relevant investigations. Histopathology revealed diagnosis of angioleiomyoma. Immunohistochemistry revealed desmin, SMA, and $\mathrm{H}$-caldesmon positivity, consistent with the diagnosis of angioleiomyoma. Our case report thus highlights the importance of including this diagnosis in the differential diagnoses of nasal masses. 


\section{Established Facts}

- Angioleiomyoma of the nose and sinuses is rare.

- Around 68 cases have been reported worldwide to date.

\section{Novel Insights}

- $\quad$ The present case is probably the first to be reported from North India.

- Angioleiomyoma should be considered in the differential diagnosis of sinonasal lesions; therefore, immunohistochemistry should be carried out routinely.

\section{Background}

Angioleiomyoma is a benign neoplasm of smooth-muscle cell origin, generally found in the uterus (95\%), skin (3\%), and gastrointestinal tract (1.5.\%) [1]. Angioleiomyomas of the head and neck account for 9.5-12.5\% of this type of tumors, and only $1 \%$ are found in the sinonasal tract $[2,3]$. The first case of angioleiomyoma in the nasal cavity was reported by Maesaka et al. [4] in 1966. Two cases have been reported from the Indian subcontinent, one in the nasal cavity and one of the septum, both from South India $[5,6]$. To the best of our knowledge, ours is the first case of angioleiomyoma of the nasal cavity to be reported from North India.

\section{Case Presentation}

A59-year-old male was referred to our Ear, Nose and Throat(ENT) Outpatient Department with a diagnosis of a left-sided nasal mass. On taking history, the man reported that he had no complaints but was diagnosed incidentally during a routine ENT checkup at his local hospital. The ENT surgeon there performed a biopsy of the said nasal mass. Histopathology showed polypoidal tissue with thick-walled blood vessels and large vascular channels lined by a single layer of endothelial cells, reported as likely angiofibroma following which he was referred to our tertiary-care hospital for further management. The patient gave history of a single episode of left-sided nasal bleeding 20 years ago, for which he underwent chemical cautery at the time.

Local examination revealed a large, pinkish, lobulated, painless mass filling the entire left nasal cavity. Nasal endoscopy was done, which showed the mass to be originating from the lateral wall of the nose. A contrast-enhanced computed tomography (CT) scan revealed a lobulated lesion showing intense heterogenous enhancement measuring $27.5 \times 15.7 \times 20.8$ $\mathrm{mm}$ within the antero-superior aspect of the left nasal cavity (Fig. 1). No obvious destruction of the nasal septum was seen. Laterally, destruction of the left nasal bone was seen. The rest of the adjacent structures appeared normal. No obvious intraorbital extension was seen. High-resolution CT of the chest, contrast-enhanced CT of the neck, and magnetic resonance imaging of the brain were all normal.

The patient was planned for surgical excision of the lesion under general anesthesia by an endoscopic/open approach. We were able to excise the lesion completely using an endoscopic approach with bipolar cautery. No significant intraoperative bleeding was encoun-

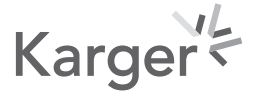




\section{Biomedicine Hub}

\begin{tabular}{l|l}
\hline Biomed Hub 2020;5:508299 \\
\hline DOI: 10.1159/000508299 & $\begin{array}{l}\text { @ 2020 The Author(s). Published by S. Karger AG, Basel } \\
\text { www.karger.com/bmh }\end{array}$ \\
\hline
\end{tabular}

Arora et al.: Sinonasal Angioleiomyoma: A Rare Entity

Fig. 1. Contrast-enhanced coronal CT image showing the tumor.

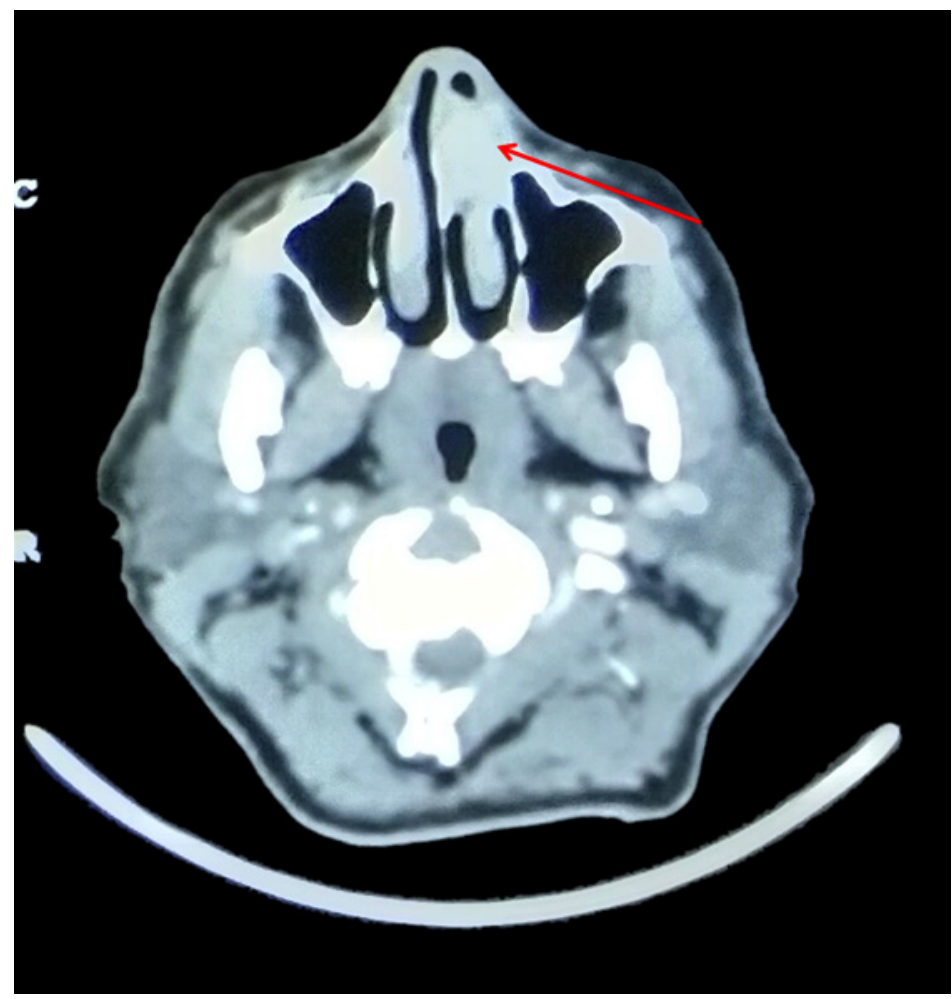

tered. The exact location of attachment of the said lesion's pedicle was superior to the inferior turbinate. The extent of attachment of the pedicle was from the most anterior point of the inferior turbinate until $3.5 \mathrm{~cm}$ (almost to the mid-point of the inferior turbinate, and above it). The postoperative course of the patient was uneventful, and he was discharged the next day after removal of the nasal pack.

Histopathological analysis of the mass revealed a well-circumscribed tumor covered by sinonasal respiratory type mucosa, composed of well-differentiated smooth-muscle cells having elongated vesicular blunt-ended nuclei with inconspicuous bundles and whorls encasing numerous vascular channels (Fig. 2). A variable adipocytic component was seen forming lobules within the lesion. No mitosis or atypia was seen. Immunohistochemistry panel was done, which revealed the following markers to be positive in spindle cells: desmin, SMA, h-caldesmon. Ki-67 index was $0.2 \%$. The tumor was CD34 negative in spindle cells and positive in blood vessel endothelium. the final diagnosis was angioleiomyoma. Serology for Eppstein-Barr virus (EBV) was negative, and cytomegalovirus (CMV) was positive.

Data and materials are available on request.

\section{Discussion}

Leiomyomas in the nasal cavity are usually located in the nasal turbinates, vestibule septum, paranasal sinuses, vestibule, and floor. Our case is unique in that the tumor attachment was between the attachments of the middle and inferior nasal turbinates [7]. Another case in which the tumor had a similar site of attachment was described by Villarreal et al. [8] in their case report.

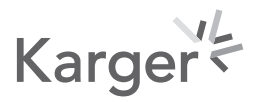




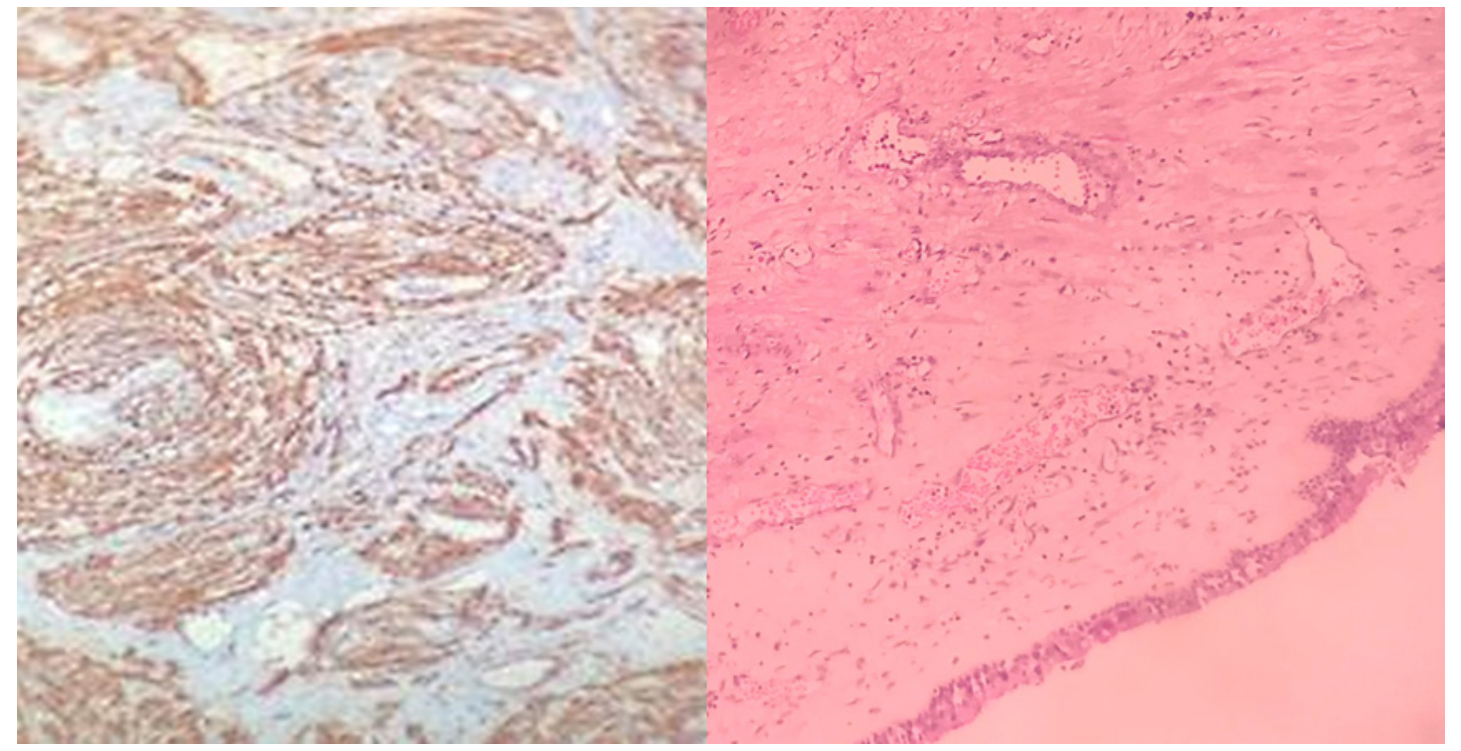

Fig. 2. Panel 1: histopathological picture of the lesion, $\times 10$ magnification, showing smooth-muscle bundles surrounding vascular channels. Panel 2: immunohistochemistry staining showing desmin, caldesmon, and S-100. ×100 magnification.

\section{Etiology and Origin}

There are 3 hypotheses to explain the origin of the sinonasal leiomyoma. They could stem from aberrant undifferentiated mesenchymal or smooth-muscle elements in the blood vessel wall, from erector pilae, or sweat gland muscles [9]. Furthermore, the idea that this tumor may be progesterone-dependent has also been proposed, and cases with progesterone receptor positivity have been reported $[10,11]$. There is also some evidence that the tumor may be associated with EBV or other viruses as well. Our patient had a negative serology for EBV; however, CMV serology was positive. Whether there is any association of CMV with the tumor is a matter for further analysis.

The World Health Organization (WHO) classified leiomyoma into 3 groups: non-vascular/ solid leiomyoma, vascular leiomyoma (angiomyoma), and epithelioid (atypical or bizarre leiomyoma and leiomyoblastoma). Morimoto [12] further defined 3 histological subtypes: capillary/solid, cavernous, and venous. Differentials include angiofibroma, hemangioma, myofibroma, hemangiopericytoma, and leiomyosarcoma [13]. As in our case, the initial biopsy done in another hospital suggested a diagnosis of angiofibroma. We would like to highlight the fact that errors in histopathological diagnosis are common if only a partial sample of the tissue is taken. Therefore, complete excision of the lesion followed by biopsy must be done to yield accurate results.

\section{Modes of Excision}

Sinonasal lesions may be excised by endoscopic or open approach, using cold steel instruments, radiofrequency, or KTP laser [14]. We used the endoscopic two-hand technique to excise the lesion, including a cuff of surrounding mucosa using bipolar cautery. Minimal bleeding was encountered, and the lesion was completely excised.

Sinonasal angioleiomyomas with adipocyte differentiation have also been identified; these were previously erroneously classified as angiomyolipoma [15]. Most recently, an angioleiomyoma was identified as a cause of isolated facial pain [16]. 


\section{Conclusion}

Sinonasal angioleiomyoma is a rare clinical entity with around 68 cases reported to date. Ours is probably the first case from the North Indian subcontinent. Etiology remains obscure though hormone dependence has been proposed.

The prognosis of sinonasal leiomyoma is favorable. No malignant transformation has been described, and recurrence is extremely rare if complete resection has been performed. In addition, the association with certain viruses needs to be further studied to be validated.

\section{Acknowledgements}

We would like to acknowledge all hospital and laboratory staff for their contribution.

\section{Statement of Ethics}

The study was approved by the institution's ethics board. The patient gave consent to the publication of his case.

\section{Disclosure Statement}

The authors declare that they have no conflicts of interest to disclose.

\section{Funding Sources}

The authors did not receive any funding.

\section{Author Contributions}

Rubeena Arora and Shubh Mahindru: involvement in the surgery and writing/editing. Komal Kathuria: pathological images.

\section{References}

1 Enzinger FM, Lattes R. Torloni Internacional H. Classificação histológica de tumores: tipagem histológica dos tumores de tecidos moles. 2a ed. Geneva, Switzerland: Organização Mundial de Saúde-Springer Verlag; 1969.

2 Wang CP, Chang YL, Sheen TS. Vascular leiomyoma of the head and neck. Laryngoscope. 2004 Apr;114(4): 661-5.

3 Chen C, Lai M, Chen C, Fang C. Vascular leiomyoma of the nasal cavity: case report. Chin Med J (Engl). 2007 Feb;120(4):350-2.

4 Maesaka A, Keyaki Y, Nakahashi T. Nasal angioleiomyoma and leiomyosarcoma-report of 2 cases. Otologia (Fukuoka). 1966;12:42-7.

5 Singh R, Hazarika P, Balakrishnan R, Gangwar N, Pujary P. Leiomyoma of the nasal septum. Indian J Cancer. 2008 Oct-Dec;45(4):173-5.

6 Michael RC, Shah S. Angioleiomyoma of the nasal cavity. Indian J Pathol Microbiol. 2009 Jul-Sep;52(3):386-8.

7 Fonseca MT, Araújo PA, Barreiros AC. Leiomioma de seio paranasal: relato de um caso e revisão da literatura. Rev Bras Otorrinolaringol (Engl Ed). 2002;68(3):436-9.

8 Villarreal Patio IM, Pinilla Urraca M, Suarez Massa D, Garca Hidalgo Y, Lopez-Cortijo C. An exceptional nasal tumor: Angioleiomyoma of the nasal cavity. J Head Neck Physicians Surg. 2015;3(3):128-133.

\section{Karger'}


9 Barr GD, More IA, McCallum HM. Leiomyoma of the nasal septum. J Laryngol Otol. 1990 Nov;104(11):891-3.

10 Tseng P-Y, Lai Y-S, Chen M-K, Shen K-H. Progesterone receptor expression in sinonasal leiomyoma: a case report and review of the literature. Int J Clin Exp Pathol. 2014 Feb 15;7(3):1224-8. eCollection 2014.

11 Marioni G, Marchese Ragona R, Fernandez S, Bruzon J, Staffieri M, Staffieri A. Expressão de receptores de progesterona em angioleiomyoma da cavidade nasal. Acta Otolaryngol. 2002;122:408-12.

12 Morimoto N. Angiomyoma (vascular leiomyoma): a clinicopathologic study. Med J Kagoshima Univ. 1973;24: 663-83.

13 Duhig JT, Ayer JP. Vascular leiomyoma: a study of 61 cases. Arch Pathol Lab Med. 1959;68:424-30.

14 Arruda MM, Monteiro DY, Fernandes AM, Menegatti V, Thomazzi E, Hubner RA, et al. Angioleiomyoma of the Nasal Cavity. Int Arch Otorhinolaryngol. 2014 Oct;18(4):409-11.

15 D'Aguanno V, Ralli M, De Vincentiis L, Remotti D, Minni A, Greco A, et al. Sinonasal Angioleiomyoma With Adipocyte Differentiation: Clinicopathologic Study of 2 Cases and Review of the Literature. Ear Nose Throat J. 2019 Sep;145561319878302.

16 Heyman J, Jones LM, Hilton JM, Cooke JS, Viswanathan H, Hayes SM. Angioleiomyoma of the inferior turbinate: a rare cause of isolated facial pain. Ann R Coll Surg Engl. 2020 Feb;102(2):e20-2. 